\title{
Influences of winning or losing in competitive situations on level of aspiration'
}

VERNON M. COPE AND HAROLD SIGALL

UNIVERSITY OF TEXAS

Level of aspiration was measured in two two-person competitive situations. Ss received pre-determined performance scores such that one $S$ won on each of three performance trials, while his competitor lost on every trial. An expectancy model was used to predict that $S s$ who lost, but whose performance improved would (1) have a higher level of aspiration than their competitors, and (2) have a higher level of aspiration than $S s$ who lost and did not improve. The results partially supported the hypotheses.

One of the most important factors which determine an individual's level of aspiration in any performance situation is his past performance in that situation. It has been shown that a history of failures and successes can shape expectancies of failure or success in later performance (Lewin et al, 1944).

The present study examines the effects of losing or winning in a two-person competitive situation. It is hypothesized that level of aspiration is, in part, determined by improvement in performance in a competitive situation and, more specifically, that Ss who lose on each trial but who improve over trials will have higher levels of aspiration than their competitors who win on each trial, but whose performance does not improve over trials. This prediction is based on the notion that expectancies of improving performance are created in the improving-loser Ss while no such expectancies are created in the winners. Losers will, therefore, see themselves as eventually surpassing their competitors. For similar reasons, it would seem likely that Ss who win against a non-improving competitor will have greater expectancies than Ss whose victories are over an improving competitor.

Method

Ss were 24 introductory psychology students at the University of Texas. Ss were tested in pairs and were told they were participating in an experiment designed to study the performances of people in competitive situations. $\mathrm{E}$ explained the performance task and scoring system: Ss were given $2 \mathrm{~min}$. to write a well-organized paragraph containing all of three words to be read to them by $\mathrm{E}$, who would then grade each paragraph and announce the scores. These scores could range between 0 and 20 , depending on the "imagination and verbal facility" expressed. Ss were then told that they would be in competition for ten trials and the winner of each trial would receive \$.50. E then announced that there would be practice trials before the competition began. It was stressed that it would be to each S's advantage to do his best in the practice trials because it would "warm him up" and would give him the opportunity to compare his performance scores with those of his competitor. The scores for the practice trials were prearranged. $\mathrm{S}_{1}$ in Competitive Condition 1 received scores of 2 , 4 , and $8, \mathrm{~S}_{2}$ in Competitive Condition 1 received scores of 10,9 , and $9 . S_{1}$ in Competitive Condition 2 received scores of 4,5 , and 5 and $S_{2}$ in Competitive Condition 2 received scores of 10,9 , and 9. After the "practice trials," each $\mathrm{S}$ filled out a questionnaire. The cructal question which measured S's level of aspiration was: "How much do you think you will win in the next 10 trials-there is a total of $\$ 5.00$ to be won-you can win anywhere between $\$ 0.00$ and $\$ 5.00$, and your competitor will win the remainder." This ended the experimental session and Ss were debriefed.

\section{Results}

Analysis of variance was used to analyze the data. The interaction was statistically significant in the predicted direction $(\mathrm{F}=6.19, \mathrm{df}=1 / 10, \mathrm{p}<.05)$. That is, Ss in the 10-9-9 group competing with $S$ s in the 4-5-5 group had higher levels of aspiration than Ss in the 10-9-9 group who competed with $\mathrm{Ss}$ in the 2-4-8 group, and $\mathrm{Ss}$ in the 2-4-8 group had higher levels of aspiration than $S s$ in the 4-5-5 group. However, Ss in the 2-4-8 group had lower levels of aspiration than their 10-9-9 competitors. The comparison between winners and losers was significant $(F=51.26, d f=$ $1 / 10, p<.01)$. Although reasonable from an intuitive point of view, this finding does not support our expectancy hypothesis. We predicted a cross-over interaction, rather than merely an interaction.

\section{Discussion}

The results tend to support the hypothesis that one of the factors in the formation of level of aspiration in two-person competitive situations, in which one individual always wins and the other always loses, is sequence of performance scores, or, more specifically, the relation of winner performance sequences with loser performance sequences. The observed interaction supports this hypothesis. We predicted that level of aspiration would be higher among the 2-4-8 losers than among the 4-5-5 losers. Although the mean differences were in the predicted direction, this difference did not reach an acceptable level of significance. However, this was due to one extreme score in the 4-5-5 group. With that score removed, the difference between the 4-5-5 and 2-4-8 groups was significant $(\mathrm{F}=5.16, \mathrm{df}=1 / 9, \mathrm{p}<.05)$. The significant interaction effect, then, is due not only to the raised levels of 
aspiration in 2-4-8 Ss as compared with 4-5-5 Ss but also to the lowered levels of aspiration of 10-9-9 Ss in Competitive Condition 1.

There is an alternative explanation for these results. One could predict a greater expectancy for 2-4-8 Ss simply because their last-trial performance is only one score-point lower than their competitors', while 4-5-5 Ss are four score-points behind on the last trial. A study is now being conducted to investigate this possibility.

The failure to confirm the prediction that Ss in the 2-4-8 group would have a higher level of aspiration than their 10-9-9 group competitors is interesting. Perhaps Ss in the 2-4-8 group raise their expectancies some, but not as high as their 10-9-9 competitors because they have yet to win or tie in the performance trials. Although 2-4-8 Ss may expect to eventually pass their competitors' performance level, they may be hesitant to predict this expectancy on a questionnaire. Perhaps a tie on the last trial would bring about a lessening of such inhibitions and a higher stated level of aspiration.

\section{Reference}

Lewin, K., Dembo, Tamara, Festinger, L., \& Sears, Pauline. In J. McV. Hunt (Ed.), Personality and the behavior disorders. New York: Ronald, 1944. Pp. 333-378.

\section{Note}

1. This research was supported by Grant MH 12357-01 from the National Institute of Mental Health awarded to Elliot Aronson. 